Slavisa Tasic

\title{
THE ILLUSION OF REGULATORY COMPETENCE
}

\begin{abstract}
The illusion of explanatory depth, which has been identified by cognitive psychologists, may play a prominent role in encouraging regulatory action. This special type of overconfidence would logically lead regulators to believe that they are aware of the relevant causes and consequences of the activities they might regulate, and of the unintended side effects of the regulatory actions they are contemplating. So, as with other cognitive biases, the illusion of explanatory depth is likely to lead to mistakes. And unlike the biases that have been the focus of so much behavioral economics, the illusion of explanatory depth is uniquely resistant to correction by those who are aware of it as a general problem and rigorously attempt to keep it under control.
\end{abstract}

By applying the findings of cognitive and evolutionary psychology to economic action, behavioral economists have pointed out that the behavior of market participants does not satisfy the norms of rationality usually assumed by the mainstream neoclassical economic model. Herbert Simon (1955) was a pioneer of behavioral economics who pointed out that neoclassical assumptions may not yield reliable predictions. Subsequent psychological research, most notably by Daniel Kahneman and Amos Tversky (I974 and I979), proposed specific biases that might lead to errors among market participants. Building on these and other findings of cognitive and evolutionary psychology, behavioral economists have developed a number of alternative models of market

Slavisa Tasic, slavisa.tasic@gmail.com, a Ph.D. candidate in law and economics at the University of Turin and Cornell University, thanks Jeffrey Friedman for valuable comments and suggestions.

Critical Review 2I (4): 423-436

(C) 2009 Critical Review Foundation
ISSN o89I-38I i print, I933-8007 online DOI: Io.Io80/089I38I090344I369 
behavior that deviate from perfect-rationality assumptions (e.g., Shleifer 2000; Barberis and Thaler 2003, I053-II28; Frey and Benz 2004).

In these psychologically informed models, market participants have bounded rationality and bounded willpower, and they are not as selfinterested as is usually assumed. More importantly, the cognitive limitations and decision-making biases of market participants are systematic, which makes them important at the aggregate level.

This paper is part of a nascent effort to apply the same type of research to the actions of the regulators who are charged with correcting or preventing aggregate-level economic mistakes and other negative social consequences. It is in the tradition of Timur Kuran and Cass Sunstein (I999), who have discussed availability cascades in regulationself-reinforcing cycles of excessive risk regulation and excessive risk perception that are spurred by the "availability bias," i.e., the tendency to overestimate the likelihood of the salient or recent events that come to mind easily. Sunstein (I994 and 2000) has pleaded for the sober use of cost-benefit analysis as a remedy for cognitive biases that might otherwise drive regulation. Chris Guthrie, Jeffrey Rachlinski, and Andrew Wistrich (200I) find that judges are not immune to some standard cognitive illusions, including anchoring, hindsight bias, egocentrism, the representativeness bias, and the framing effect. David Hirshleifer (2008) points to the biases that financial regulators may face, including salience and vividness effects, overconfidence, xenophobia, and scapegoating. These are, however, isolated and limited attempts to apply non-rational choice, empiricist approaches to the behavior of regulators.

With the exception of Hirshleifer (2008), these scholars do not argue that the possibility of successful regulation is fundamentally limited by cognitive factors, but advocate the use of behavioral economics as an instrument to improve regulation. But certain findings of cognitive psychology suggest that a great deal of regulation is likely to fail, regardless of the level of cognitive psychology that informs it. Above all, the very decision to engage in regulation might be a consequence of behavioral biases, such that a regulator of, say, financial markets who is trying to curb "irrational exuberance" may craft the regulations in a way that tries to avoid the specific biases that have been identified by cognitive psychologists, while still erring in thinking that the regulation will improve matters.

One reason this may happen is the "action bias," which has been documented in other areas of behavior (Bar-Eli et al. 2005). Regulators 
who were afflicted with action bias would be likely to respond to a new problem with a new regulation, even though inaction or the removal of a previous regulation may be the better response. Thus, overreaction is a familiar phenomenon following a crisis. Overreaction in air-travel regulation after September I I, by increasing the cost of flying, shifted travelers towards driving. But driving is, on average, a riskier means of transportation than flying, so this regulation may have caused a significant number of deaths (Blalock, Kadiyali, and Simon 2005). After the collapse of Enron, the introduction of stringent corporate-conduct regulation, through the Sarbanes-Oxley Act, may have diverted corporate resources away from actual risk monitoring toward formal compliance with "transparency" measures that only add to information clutter. It discouraged companies from going public in the United States and disturbed the market structure by putting small public companies into a particularly disadvantaged position (Rezzy 2007; Piotroski and Srinivasan 2008). ${ }^{1}$

It should also be noted that those who choose to become, say, financial regulators are likely, ceteris paribus, to believe that such regulation is necessary. Whatever beliefs initially motivate this conviction may be reinforced cognitively by the selective perception and retention of information that confirms the initial belief (confirmation bias), in what Jeffrey Friedman (2006, drawing on cognitive research in Lord, Ross, and Lepper I979 and Lodge and Hamill I986) has called a "spiral of conviction." Similarly, at the affective level, Ziva Kunda (1987) has demonstrated that people confirm their beliefs through "motivated reasoning" (cf. Lundgren and Prislin I998). These cognitive and affective sources of growing confidence in one's initial beliefs, in turn, may be reinforced by "motivated skepticism," which is to say emotional resistance to counter-arguments (Johnston I996; Zuwerink and Devine I996; Taber and Lodge 2006). The net result, in the case of regulators, may be an extra cognitive bias to action, buttressed by standard emotional processes of dogmatization.

\section{Overconfidence about Complex Phenomena}

Yet another cognitive bias might play a role in buttressing regulators' putative inclination toward action: "the illusion of explanatory depth."

The illusion of explanatory depth is a variant of overconfidence. Overconfidence, in turn, is the illusion that our personal abilities, 
including our knowledge, are better than they really are. Numerous experiments have shown that we regularly overestimate the extent of our own knowledge (e.g., Fischoff, Slovic, and Lichtenstein 1977). When people are asked to guess the probability that their answers in simple tests of factual knowledge are correct, they systematically overestimate the level of their knowledge. Similarly, behavioral economists have pointed out that investors tend to be overconfident in their predictions of future trends, which results in more trading than is rational.

Overconfidence is not limited to our knowledge of facts or our perceptions of our predictive abilities. It is also present in the perceptions of our own comprehension, competence, and understanding of narratives and other phenomena that lie outside of us. Students in experiments who are going to be tested on a given subject tend to feel that they understand the material better than they do, and even the objective test results do not easily convince them that they had had an excessive belief in the adequacy of their understanding. Experiments in textual understanding show that self-assessments of the level of comprehension of a text are poor predictors of the real level of comprehension (Glenberg and Epstein I985; see also Jacoby, Bjork, and Kelley I994, 57-80).

The texts in question were not particularly difficult. Any scholar, however, will be familiar with the difficulty of truly attaining a clear understanding of a complex text. Leonid Rozenblit and Frank Keil (2002) used the phrase the illusion of explanatory depth (which they abbreviate to IOED) to describe how, in a series of experiments, people systematically overestimate their understanding of complex phenomena. The IOED is the belief that we understand the causes, effects, and inner workings of complex mechanisms, events, and processes much better than we actually do.

Rozenblit and Keil faced people with specific questions to test the depth of their understanding - asking them, for example, to explain how a helicopter can switch from hovering in place to flying forward-and found that people who thought they understand the basic physics and mechanics behind a helicopter flight could not answer correctly. Only after hearing an expert explanation would participants in the experiments realize that they had been overconfident and revise downward their estimates of their initial understanding.

Rozenblit and Keil (2002) were able to distinguish the IOED from other forms of overconfidence, such as overconfidence about knowledge 
of facts (e.g., the capital cities of different countries), overconfidence about procedural knowledge (e.g., how to operate a device), and overconfidence about the ability to reproduce narrative scenarios (real or fictional). They found that overconfidence is worst when it comes to explaining complex phenomena. The IOED is not only qualitatively different from the other three knowledge illusions; it is also more powerful.

It might be thought that participants in the experiments initially reported a higher level of understanding than they possessed so as to avoid embarrassment. But that is unlikely, since the participants reported that they did not think that the kind of knowledge in question was important. Furthermore, the experiments showed that people overestimate not only their own but also others' understanding and explanatory abilities. This is another indication that the IOED differs from other forms of overconfidence, and that it stems from people's oversimplification of the nature and depth of the problem at hand rather than from excessive self-regard.

Rozenblit and Keil (2002) argue that the IOED is a byproduct of knowing something more general or more difficult to articulate about a phenomenon than the aspect that people are asked to explain. The illusion occurs when we have a general, superficial knowledge about some obvious patterns, and confuse this with insight about the mechanics of the phenomenon. We rely on visible aspects to construct an understanding of how things work, but that understanding is, in cases of complex phenomena, in fact very shallow in comparison to the true one. A somewhat different possibility is that we tend to confuse levels of explanation when there are parallel explanations on different levels of understanding. We may understand the immediate causes of an event but not know what is behind these causes, and so on, further and further to root causes. In the IOED, we see the visible cause-and-consequence mechanism, understand the immediate level of explanation, and mistakenly believe that that's all there is to it.

An everyday manifestation of the IOED is that people vastly underestimate the work and knowledge involved in making ordinary everyday devices. Even things as simple as a hammer and a shovel rely on factors such as relative weight and torque that go unnoticed by most people, but which are essential to their efficiency and reliability as tools. Thus, most of us would, if asked, tend to think of these tools as simple to make, even though they actually originate in complicated engineering processes or long sequences of trial and error. 


\section{The Illusion of Explanatory Depth in Political Contexts}

Modern society is precisely the type of phenomenon that is most likely to foster the IOED. It is a complex order whose skeletal patterns are recognizable on the surface. While we think we have a good understanding of how it works, the causal relationships within it-generated by millions or, in the case of the modern economy, billions of people who interact with each other anonymously, seeking all sorts of unknown goals based on all sorts of unknown perceptions - are more complicated than we usually think.

Even causal relationships that economists, for instance, think that they understand tend to be stochastic. Economists can with some certainty predict the direction of effects of different causes (such as price ceilings, which generally lead to shortages), but their ability to predict the magnitude of the effects is very limited. Moreover, their knowledge of causes is reduced to a few large and visible effects, while there are many other causalities that they cannot reliably predict. These causalities may produce the unintended consequences that so often frustrate our actions, or that make the solution worse than the problem. It is precisely our limited knowledge and limited understanding that make these consequences so surprising to us-"black swans," as it were.

The evidence for the claim that regulators may be particularly prone to the IOED is merely suggestive thus far, and for reasons I will discuss, it may have to remain that way. But an experiment conducted by Dietrich Dorner (1997) may add some weight to this suggestion. Dorner's experiment had participants use computer-simulation models to undertake land-use planning. As in the real world, the simulations included competing goals and multiple interdependencies among policy tools. But the participants did not appreciate the complexity of the situation. They focused on a few key variables, neglecting the importance of other factors. They were largely ignorant of the interdependencies in the system, focusing on the immediate effects of individual problems and neglecting the potential ramifications of their actions. In short, they focused on the immediate, visible problems without much regard to unintended consequences.

The most extreme example of underestimating the problem of managing complex aggregate structures may have been the Soviet Union's attempt to undertake central economic planning in the I920s. A dusty chapter of intellectual history shows that this effort commanded 
considerable support from expert academics in the West, whose understanding of economics told them that the task of arriving at the right prices to attach to the myriad goods in an economy was a simple matter of solving simultaneous supply and demand equations, just as was routinely done on the economist's blackboard (Lavoie I985). Joseph Schumpeter (I950, I72-86), of the Harvard economics department, spoke for the discipline as a whole in declaring these "market socialist" economists the winners in the debate with dissident economists over "socialist calculation" (of prices).

Today, even though central planning has been discredited, the operating assumption in mainstream economics and policy analysis is that the important consequences of regulatory measures can be known to the regulators, just as economists used to think that prices could be determined in some manner similar to blackboard calculation. The possibility of regulatory error is not seriously considered in policy formulation, and the concept of unanticipated negative ramifications is largely absent from policy analysis. In some sense, this is almost a necessity, since unlike in the Dorner experiment, there is no higher expert, standing above the policy analysts and regulators who come up with new regulations, who can tell us that the analysts and regulators are ignoring key interdependencies and other complexities. Assuming that the regulators are doing their best to craft effective regulations, then naturally they are trying to anticipate unintended consequences. The question, however, is whether they are any better equipped to do so than were Lenin's central planners 90 years ago.

As noted, other types of cognitive bias might be addressed, in principle, by regulators who tried to keep in mind the findings of behavioral economics and of cognitive psychology more generally. But when it comes to the illusion of explanatory depth, it is difficult to envision what a regulator who is aware of the problem in the abstract might do about it in practice. In the Rozenblit and Kiel experiments, subjects became aware that they had overestimated their understanding of complex phenomena once expert explanations of the phenomena were offered to them. But that simply moves the level where the IOED might occur back a step, to the experts who might advise regulators.

The record of economists in the socialist-calculation debate-or in failing to anticipate the more recent financial crisis-suggests that in the social sciences, even "experts" are prone to the IOED. Daron Acemoglu (2009) and David Colander et al. (2009) have outlined in excruciating 
detail the theoretical oversimplifications that caused economists to miss the crisis and to be at a loss to explain it once it had happened. Jeffrey Friedman (2009) points out that the regulations that may unintentionally have caused the crisis were all in line with well-established economic theories. If so, then it stands to reason that the regulators were not merely ignorant of the unintended consequences of their actions; they were also unaware of their ignorance.

This is a situation comparable to that facing entrepreneurs, who, as Israel M. Kirzner (I973) pointed out, are "radically" ignorant. They are faced with more than stochastic ignorance; they are also ignorant of specific things that they need to know but do not know, and they are unaware of this ignorance: They face "unknown unknowns." (This is why they often make losses instead of profits.) Regulators subject to the IOED are in a similar position. Not only do they not know how society will react to regulatory fine tuning, but they are not aware of their own ignorance-or else they would not do the fine tuning. The IOED would foster regulators' conviction that they understood what they were regulating, even if their understanding were severely limited. Unlike entrepreneurs, however-who would also be prone to the IOED-the actions, or overreactions, of regulators are not subject to competitive vetting through tests such as those administered by profit or loss. Thus, we would expect the IOED, like other cognitive biases, to be mitigated in markets through the weeding-out of entrepreneurs whose judgments do turn out to be simplistic. Friedman (2009) points out that there is no similar competition among regulations, since each of them has the force of law.

\section{Is the Illusion of Explanatory Depth Important?}

Are regulators actually subject to the IOED? Laboratory research that would test this hypothesis has not yet been done, and if the problem is real, the research probably could not be done satisfactorily. Presumably psychologists could establish that regulators are as prone as anyone else to the IOED. But one could not test regulators for the IOED in their own field of regulatory authority. Doing so would require designating some other expert's judgments as showing the true workings of, say, the banking system. But this procedure would beg the question of whether the regulator's own understanding of his area of authority, or the understanding 
of the experts who agree with him, is indeed simplistic in comparison to that of the "true" expert.

However, since regulators would not deliberately produce regulations that failed, one might use regulatory failures as a first approximation of the presence of the IOED. In the United States, alcohol prohibition in the I920s famously instigated the emergence of organized crime, with terrible unanticipated consequences; and prohibition most likely did not even succeed in its immediate purpose of significantly reducing drinking (Dills, Jacobson, and Miron 2005). The introduction of mandatory seatbelts in the I960s reduced the number of deaths in any given car accident, but since people feel safer when driving with seatbelts, this regulation may have made driving riskier and finally resulted in an overall increase of the number of accidents, and in an increase in fatalities for bicyclists, motorcyclists, and pedestrians (Peltzman I973). The Americans with Disabilities Act, which had the admirable intention of helping people with disabilities find employment or keep their jobs, apparently ended up producing the opposite outcome: By increasing the cost of firing people with disabilities, the ADA unintentionally increased the cost of hiring them. Thus, the unemployment rate of people with disabilities actually increased after the introduction of the Act (Acemoglu and Angrist 200I; Peltzman 2007). The regulation of pharmaceuticals by the Food and Drug Administration slowed down the introduction of new drugs and may, on net, have caused more unnecessary death and suffering than it prevented (Gieringer I985; Higgs I995; Kazmin I990; Klein 2000). Subsidies and regulatory measures aimed at encouraging the use of alternative sources of energy resulted in higher prices for American corn, which was diverted from world markets into ethanol production (McNew and Griffith 2005). This, in turn, may have had the effect of harming the poor in less developed countries. And these are only some of the visible unintended consequences that we are able to isolate and quantify.

One could go on listing regulatory failures, but such an exercise would be insufficient to establish exactly what (I have argued) is necessarily missing when it comes to complex phenomena: a sense of the magnitudes involved on each side of the equation. Such lists might be misleading because it is possible that regardless of the failures, the successes are less visible or have been insufficiently sampled in lists such as those I have just presented. If so, it would suggest that the effect of the IOED is insignificant. Moreover, one may legitimately dispute any claim that an item on a list of harmful outcomes is, in fact, caused by a regulation. "Experts" 
can be found on both sides, each side claiming that the other is simplistic and that their own interpretation provides more explanatory depth.

Clifford Winston (2006) of the Brookings Institution recently undertook a comprehensive survey of cost-benefit studies of American regulation. His conclusion is that in every case except pollution control, the costs far outweighed the benefits. But the precision of such studies is suspect. And the researchers who produce them cannot possibly look for costs or benefits that they have not thought of - that is, costs or benefits of which they are radically ignorant. Again, then, the expert evaluating the regulator may himself be subject to the illusion of explanatory depth when he tries to establish the scope of unintended negative consequences. Thus, even if we grant that, ceteris paribus, regulators are prone to overestimate the beneficial consequences of their actions, we cannot say conclusively whether the unintended harmful consequences of their actions outweigh both the intended and the unintended benefits of their actions.

Although that problem cannot be avoided, it might be mitigated if we could find instances where all of the hypotheses converge on regulatory failures that had extremely severe consequences. The financial crisis may be one such case. There is at least wide agreement that Federal Reserve policy played a very significant role in fostering the crisis (Gjerstad and Smith 2009; Stiglitz 2009; Taylor 2009); other scholars also blame regulatory interventions in the housing market (Taylor 2009; Wallison 2009). Still others point to minimum-capital regulations that encouraged banks to invest in AA- or AAA-rated mortgage-backed securities (Acharya and Richardson 2009; Jablecki and Machaj 2009). Moreover, the firms that issued those ratings were themselves the beneficiaries of regulations that had, over the course of seven decades, insulated them from competition (White 2009). And even scholars who blame the failure to regulate banking with sufficient vigor (e.g., Bhidé 2009; Gjerstad and Smith 2009; Posner 2009; and Stiglitz 2009) acknowledge that regulators themselves tended to oppose stricter regulation because of their confidence in the self-correcting powers of free markets - which shows (if these scholars are correct) that the IOED knows no ideological boundaries.

Other scholars (e.g., Akerlof and Shiller 2009) have appealed to behavioral economics to explain the crisis, positing "irrational exuberance" in the housing market, for example. There are also irrationality- (or, better, emotion-) based theories of business cycles, such as that of Hyman Minsky (I986). However, these theories were well known prior to the crisis; it was, in fact, Alan Greenspan himself who used the term 
"irrational exuberance" to describe the dot-com bubble, and there was lively debate about whether the explosive rise in housing prices from 200 I to 2007 constituted a bubble (Posner 2009, 82-92). Greenspan, however, did not think he knew how to identify a bubble, as opposed to a justified runup in prices (due to such factors as rising American population and wealth and shrinking supplies of land in desirable cities). He had the power to pop the bubble by raising interest rates, but he declined to use this power because he thought that doing so might, in effect, be caused by the IOED! Does this count as a regulatory failure, and thus a confirmation of the IOED?

If so, it is only because at this point in the growth of the regulatory state, there is little that regulators do not have the power to do, such that both acts of commission and acts of omission that turn out badly can be classified as instances of the IOED at work. If that seems like stacking the deck in favor of the significance of the IOED, however, we should remember that the IOED can be present only if the subject is trying to understand a complex phenomenon that, by virtue of its complexity, may defy human understanding. The ultimate question with which we have been grappling, then, is whether modern societies are, in that sense, truly "complex" phenomena.

The fact that even experts who do think that they understand modern society well enough to regulate it disagree among themselves about what caused a crisis such as the one we have just experienced suggests that modern societies are, indeed, complex-even if they do not defy every single human being's understanding. Some experts will turn out to be right and others will turn out to be wrong. But the practical question is how we can know in advance which experts' predictions are based on a sufficiently deep understanding of the complexities involved, and which of them are based on the IOED.

\section{NOTE}

I. Hirshleifer 2008 points out that presence salience and availability heuristics after big events, such as the collapse of Enron, have been at work in this case.

\section{REFERENCES}

Acemoglu, Daron. 2009. "The Crisis of 2008: Lessons for and from Economics." Critical Review 2 I (2-3): I 85-94. 
Acemoglu, Daron, and Joshua Angrist. 200I. "Consequences of Employment Protection? The Case of the Americans with Disabilities Act." The Journal of Political Economy I99(5): 9I5-57.

Acharya, Viral V., and Matthew Richardson. 2009. "Causes of the Financial Crisis." Critical Review 2I(2-3): I95-2IO.

Akerlof, George A., and Robert J. Shiller. 2009. Animal Spirits: How Human Psychology Drives the Economy, and Why It Matters for Global Capitalism. Princeton: Princeton University Press.

Barberis, Nicholas, and Richard Thaler. 2003. "A Survey of Behavioral Finance." In G. M. Constantinides, M. Harris, and R. M. Stulz, eds., Handbook of the Economics of Finance, vol. I. Kidlington, England: Elsevier.

Bar-Eli, Michael, Ofer H. Azar, Ilana Ritov, Yael Keidar-Levin, and Galit Schein. 2007. "Action Bias among Elite Soccer Goalkeepers: The Case of Penalty Kicks." Journal of Economic Psychology 28(5): 606-2 I.

Bhidé, Amar. 2009. "An Accident Waiting to Happen." Critical Review 2I(2-3): 2 I I-47.

Blalock, Garrick, Vrinda Kadiyali, and Daniel H. Simon. 2005. "The Impact of 9/ I I on Road Fatalities: The Other Lives Lost to Terrorism." Social Science Research Network. http://ssrn.com/abstract $=677549$

Colander, David, Michael Goldberg, Armin Haas, Katarina Juselius, Alan Kirman, Thomas Lux, and Brigitte Sloth. 2009. "The Financial Crisis and the Systemic Failure of the Economics Profession." Critical Review 2I(2-3): 24967.

Dills, Angela K., Mireille Jacobson, and Jeffrey A. Miron. 2005. "The Effect of Alcohol Prohibition on Alcohol Consumption: Evidence from Drunkenness Arrests." Economic Letters 86(2): 279-84.

Dorner, Dietrich. 1997. The Logic of Failure: Recognizing and Avoiding Error in Complex Situations. Cambridge, Mass.: Perseus Press.

Fischoff, Baruch, Paul Slovic, and Sarah Lichtenstein. I977. "Knowing with Certainty: The Appropriateness of Extreme Confidence." Journal of Experimental Psychology: Human Perception and Performance 3: 552-64.

Frey, Bruno, and Mattthias Benz. 2004. "From Imperialism to Inspiration: A Survey of Economics and Psychology." In John Davis, Alain Marciano, and Jochen Runde, eds., The Elgar Companion to Economics and Philosophy. Northampton, Mass.: Edward Elgar.

Friedman, Jeffrey. 2006. "Democratic Competence in Normative and Positive Theory: Neglected Implications of "The Nature of Belief Systems in Mass Publics." Critical Review I 8(I-3): i-xliii.

Friedman, Jeffrey. 2009. "A Crisis of Politics, Not Economics: Complexity, Ignorance, and Regulatory Failure." Critical Review 2 I (2-3): I 27-83.

Gieringer, Dale. I985. "The Safety and Efficacy of New Drug Approval." Cato Journal 5(I): I77-20I.

Gjerstad, Steven, and Vernon L. Smith. 2009. "Monetary Policy, Credit Extension, and Housing Bubbles: 2008-1929." Critical Review 2 I (2-3): 269-300.

Glenberg, Arthur, and William Epstein. I985. "Calibration of Comprehension." Journal of Experimental Psychology: Learning, Memory, and Cognition I I: 702-08. 
Guthrie, Chris, Jeffrey Rachlinski, and Andrew Wistrich. 200I. "Inside the Judicial Mind." Cornell Law Review 86(4): 777-830.

Higgs, Robert, ed. I995. Hazardous to Our Health? FDA Regulation of Health Care Products. Oakland: Calif.: Independent Institute.

Hirshleifer, David A. 2008. "Psychological Bias as a Driver of Financial Regulation." European Financial Management I4(5): 856-74.

Jablecki, Juliusz, and Mateusz Machaj. 2009. "The Regulated Meltdown of 2008." Critical Review 2I (2-3): 30 I-28.

Jacoby, Larry, Robert Bjork, and Colleen Kelley. I994. "Illusions of Comprehension, Competence and Remembering." In D. Druckman and R. A. Bjork, eds., Learning, Remembering, Believing: Enhancing Individual and Team Performance. Washington, D.C.: National Academy Press.

Johnston, Lucy. I996. "Resisting Change: Information-Seeking and Stereotype Change." European Journal of Social Psychology 26: 799-825.

Kahneman, Daniel, and Amos Tversky. I974. "Judgment under Uncertainty: Heuristics and Biases." Science I 85: I I24-3 I.

Kahneman, Daniel, and Amos Tversky. 1979. "Prospect Theory: An Analysis of Decisions under Risk." Econometrica 47: 3 I 3-27.

Kazman, Sam. I990. "Deadly Overcaution: FDA's Drug Approval Process." Journal of Regulation and Social Costs I(I): 35-54.

Kirzner, Israel. I973. Competition and Entrepreneurship. Chicago: University of Chicago Press.

Klein, Daniel. 2000. "Policy Medicine versus Policy Quackery: Economists Against the FDA." Knowledge, Technology \& Policy I3(I): 92-Ior.

Kunda, Ziva. I987. "Motivated Inference: Self-Serving Generation and Evaluation of Causal Theories." Journal of Personality and Social Psychology 53(4): 636-47.

Kuran, Timur, and Cass R. Sunstein. I999. "Availability Cascades and Risk Regulation.” Stanford Law Review 5I(4): 683-768.

Lavoie, Don C. I985. Rivalry and Central Planning: The Socialist Calculation Debate Reconsidered. Cambridge: Cambridge University Press.

Lodge, Milton, and Ruth Hamill. 1986. "A Partisan Schema for Information Processing." American Political Science Review 80: 505-I9.

Lord, Charles, Lee Ross, and Mark R. Lepper. I979. "Biased Assimilation and Attitude Polarization: The Effects of Prior Theories on Subsequently Considered Evidence." Journal of Personality and Social Psychology 37(I I): 2098-I09.

Lundgren, Sharon M., and Radmilla Prislin. I998. "Motivated Cognitive Processing and Attitude Change." Personality and Social Psychology Bulletin 24(7): 7I 5-26.

McNew, Kevin, and Duane Griffith. 2005. "Measuring the Impact of Ethanol Plants on Local Grain Prices." Review of Agricultural Economics 27(2): I64-80.

Minsky, Hyman. 1986. Stabilizing an Unstable Economy. New Haven: Yale University Press.

Peltzman, Sam. I973. "An Evaluation of Consumer Protection Legislation: The I962 Drug Amendments." Journal of Political Economy 8 I(5): I049-9I.

Peltzman, Sam. 2007. "Regulation and the Wealth of Nations: The Connection between Government Regulation and Economic Progress." New Perspectives on Political Economy 3(2): I 85-204. 
Piotroski, Joseph D., and Suraj Srinivasan. 2008. "Regulation and Bonding: The Sarbanes-Oxley Act and the Flow of International Listings." Rock Center for Corporate Governance at Stanford University, Working Paper No. I I.

Posner, Richard A. 2009. A Failure of Capitalism: The Crisis of 'o8 and the Descent into Depression. Cambridge, Mass.: Harvard University Press.

Rezzy, Oleg. 2007. "Sarbanes-Oxley: Progressive Punishment for Regressive Victimization." Houston Law Review 44(I): 95-I29.

Rozenblit, Leonid, and Frank Keil. 2002. "The Misunderstood Limits of Folk Science: An Illusion of Explanatory Depth." Cognitive Science 26: 52 I-62.

Schumpeter, Joseph A. I950. Capitalism, Socialism, and Democracy, 3rd ed. New York: Harper \& Row.

Shleifer, Andrei. 2000. Inefficient Markets: An Introduction to Behavioral Finance. Oxford: Oxford University Press.

Simon, Herbert. I955. "A Behavioral Model of Rational Choice.” Quarterly Journal of Economics 69: 99-I I 8.

Stiglitz, Joseph E.. 2009. "The Anatomy of a Murder: Who Killed America's Economy?” Critical Review 2 I (2-3): 329-39.

Sunstein, Cass R. I994. "On Costs, Benefits, and Regulatory Success: Reply to Crandall." Critical Review 8(4): 623-34.

Sunstein, Cass R. 2000. "Cognition and Cost-Benefit Analysis." The Journal of Legal Studies 29(2): I059-I I03.

Taber, Charles S., and Milton Lodge. 2006. "Motivated Skepticism in the Evaluation of Political Beliefs." American Journal of Political Science 50(3): 755-69.

Taylor, John B. 2009. "Economic Policy and the Financial Crisis: An Empirical Analysis of What Went Wrong." Critical Review 2I (2-3): 34 I-64.

Wallison, Peter J. 2009. "Cause and Effect: Government Policies and the Financial Crisis." Critical Review 2I (2-3): 365-76.

White, Lawrence J. 2009. "The Credit-Rating Agencies and the Subprime Debacle." Critical Review 2 I (2-3): 389-99.

Winston, Clifford. 2006. Government Failure Versus Market Failure: Microeconomics Policy Research and Government Performance. Washington, D.C.: AEI-Brookings Institution.

Zuwerink, Julia, and Patricia G. Devine. I996. "Attitude Importance and Resistance to Persuasion: It's Not Just the Thought that Counts." Journal of Personality and Social Psychology 70(5): 93 I-44. 